\title{
The Two Faces of SLA: Mental Representation and Skill
}

\author{
BiLl VAnPatTEN* \\ Texas Tech University
}

Received: 17 May 2010 / Accepted: 28 June 2010

\begin{abstract}
In this essay, I argue for viewing mental representation and skill as distinct components of language acquisition. My claim is that language is not a monolithic entity-not a new concept, but one that is often overlooked by instructors and some scholars. I examine language as being (minimally) composed of mental representation and skill. Representation refers to the abstract and implicit knowledge that underlies all language. Skill refers to the use of language, especially fluency (the intersection of speed and accuracy).By thinking about language as at least the distinction between representation and skill, we might better sort out some of the issues related to adult SLA, namely the role that instruction has, and what instruction can actually impact.
\end{abstract}

\section{KEYWORDS:}

Second language acquisition, L2 mental representation, L2 skill, language instruction.

\section{RESUMEN}

En este trabajo defiendo el supuesto de que tanto la representación mental como las destrezas (lingüísticas) deben ser tomadas como componentes diferenciados de la adquisición lingüística. Mi tesis es que el lenguaje no es una entidad monolítica -tesis no nueva, pero frecuentemente dejada de lado por profesores y estudiosos. Analizo el lenguaje como un compuesto de representación mental y destrezas. La representación se refiere al conocimiento abstracto e implícito que subyace en el lenguaje. Las destrezas hacen referencia al uso de la lengua, especialmente a la fluidez (intersección entre velocidad y precisión). Entendiendo el lenguaje de esta manera, distinguiendo entre representación y destrezas, será posible superar algunos de los problemas relativos al aprendizaje de lenguas por los adultos, y muy especialmente el cometido de la enseñanza y lo que ésta puede producir.

\section{PALABRAS CLAVE:}

Adquisición de segundas lenguas, representación mental en L2, destreza en L2, enseñanza de lenguas.

\footnotetext{
*Address for correspondence: Bill VanPatten. Texas Tech University. $5805111^{\text {th }}$ Street. Lubbock TX, 79424 USA. E-mail: aliasbvp@gmail.com
} 
In this essay, I will argue something that ought to be self-evident but is often overlooked in both theoretical and applied L2 circles: language is multifaceted and not reducible to a single concept. In simplest terms, this means that language consists of two broad domains: (1) mental representation, and (2) skill (use), although within each domain there are separable sub-domains (e.g., syntax, phonology, lexicon, semantics, and so on in mental representation; and reading, writing, speaking, and so on, in skill). The implications of such a view are that the development of different parts of language may respond to different stimuli in the environment. What is more, some domains may be more or less amenable to explicit instruction and practice while others are stubborn or resistant to external influences.

\section{LANGUAGE AS MENTAL REPRESENTATION}

\section{I.1. What is Mental Representation of Language?}

I take mental representation to mean the abstract, implicit, and underlying linguistic system in a speaker's mind/brain (VanPatten \& Benati, 2010, p. 107). By abstract I mean that the linguistic system is not something akin to a set of textbook or prescriptive rules, but instead is a collection of abstract properties from which rule-like behavior is derived (e.g., Harley \& Noyer, 1999; Jackendoff, 2002; Radford, 2001; Rothman, 2010; White, 2003). From a Minimalist Perspective (Chomsky, 1995; Herschensohn, 2000; Radford, 1997) these abstract properties include universal constraints on language (e.g., Structure Dependency, Extended Projection Principle, Overt Pronoun Constraint, Binding) as well functional categories and features (e.g., Tense, Agreement, Aspect, Number) that can vary across languages (parametric variation). As an example, let's look at auxiliary do in yes-no questions in English. Typical yes/no question are formed using $d o$, while other options, such as subject-verb inversion, are prohibited as in (1) and (2) below. The reverse is true in a language like Spanish that has subject-verb inversion and lacks an auxiliary like do as in (3).

(1) Does John live near the university?

(2) *Lives John near the university?

(3) ¿Vive Juan cerca de la universidad?

While we can describe the use of do in questions with a statement like "insert do for yes-no questions and invert with the subject," in a mental grammar of English do is the result of a series of interactions between abstract features of the grammar. Comp, which is the head of the Complementizer Phrase (CP), contains the feature +STRONG. Strong Comp forces the 
movement of do out of the Inflectional Phrase (Infl) where it is generated to carry Tense features given that English is +STRONG for Tense as well. These kinds of syntactic operations occur when features are +STRONG in a language, requiring lexical insertion or movement of a constituent into a phrase to get that feature checked. Thus, our textbook type rule of "insert do and invert subject and auxiliary verb” is not what actually exists in the grammar or in people's minds; it is a specific short hand way to describe a particular consequence of more abstract principles of the grammar.

By implicit I mean that the content of the mental representation exists outside of awareness: speakers may know they have mental representation for language but they generally do not know the content of that representation. In the example just given, speakers of English (except linguists) do not consciously know about CPs, Comp and the concept of +/-STRONG as a parametric variation of features across languages. They can accept sentences such as Do you know the way to San Jose? as possible English sentences while rejecting *Know you the way to San Jose? as possible English sentences. However, they cannot articulate why based on the abstract principles of grammar that underlie their judgments. This knowledge exists outside of their awareness.

Finally, by underlying, I mean that the linguistic system underlies all surface manifestations of language. What is produced by a speaker must conform to the content of this mental representation, be it the utterances of two-year old or the utterances of a 30-year old. Each has an underlying grammar that cannot be violated by the output mechanisms responsible for speech. At the same time, the parsing mechanism used by listeners and readers to comprehend sentences must ensure that all requirements of the mental representation are met during real-time comprehension. Otherwise, the listener/reader experiences the doubletake (e.g., “Huh?” when hearing or reading something). In the grammar of English for native speakers, as one example, the verb put has an underlying representation that includes semantic information (e.g., an agent projects into the subject position, a theme projects into the object position, a goal that projects into a prepositional phrase). If any one of these elements is absent in a stretch of speech (e.g., John put the cake), the parser stops and says “Whoa! Isn’t something missing in what I just heard?” Because English is not a null subject language, the parser would also stop and do a double-take when processing a sentence like Is raining today.

The contents of the mental representation include all formal features of language (e.g., syntax, phonology, lexicon-morphology) as well as the semantics that relate to structure. As such, one of the main functions of the mental representation is not just to ensure that speakers know what is possible in a language but also what is impossible. In the phonological domain, for example, the speaker of English "knows" that schwaing vowels are possible in unstressed 
syllables but impossible in stressed syllables. In the syntactic domain, the speaker of English "knows" that complementizers such as that can be omitted in sentences like John thinks (that) Bill is a nifty linguist but can’t be omitted in others, such as *John complains Bill is too nice. In the lexicon-morphology domain, a speaker of English knows that adjectives like honest take dis- to form opposite meanings (honest/dishonest) but adjectives like faithful can't (faithful/*disfaithful), and that verbs like submit and do can take re (resubmit, redo) but verbs like sleep and drink can't (*resleep, *redrink).

To summarize, the mental representation of language in a speaker's mind/brain consists of abstract properties of language that exist outside of the speaker's ability to describe. These properties include all of the formal domains of language including syntactic, lexical, phonological, morphological properties, as well as certain properties of semantics.

\section{I.2 How does Mental Representation Develop?}

The development of a mental representation is deceptively simple to describe. It is the result of three different factors working together: (1) input, (2) Universal Grammar, and (3) the parsing/processing mechanisms that mediate between the other two.

Input is the language to which everyone is exposed in communicative settings, be it in or out of classrooms. By communicative I mean that the sample speech stream the person is exposed to exists to communicate some kind of meaning; it is not a sample of language to illustrate how language works.

Universal Grammar (UG) is the uniquely human knowledge system that is genetically determined. It consists of abstract principles to which all languages must adhere, as well as variations regarding certain principles (e.g., parameters). We can see both principles and parameters at work in question formation. UG allows for wh-elements to move when forming questions, giving rise to both John knows what? and What does John know? (the wh-element moves from its object-of-verb position to occupy a "higher" position in the sentence). But not all languages allow wh-movement. Chinese, for example, only allows the equivalent of John knows what? Thus, parametrically, languages can be +/- wH- MOVEMENT. However, UG stipulates that there are restrictions on wh- movement; languages are not free to move whelements from just any position. So, although English is +WH- MOVEMENT, it disallows the extraction of wh- elements from what are traditionally called "islands," as in * What does John wonder who bought? The what cannot be moved from its object-of-verb position in the embedded clause (e.g., John wonders who bought what).

Parsing and processing refer to the syntactic computations made during real-time comprehension. When listening to (or reading) a stretch of language, we automatically assign 
it structure in that we must identify the verb, determine what the relationships of any nouns are to that verb, which phrases modify which parts of the utterance, and so on. We also identify and tag particular words to mean particular things, including any inflections or grammatical markers that indicate meaning or function (e.g., -ed on a verb indicates pastness, the in front of a noun phrase indicates a particular entity presumably known to the speaker and listener). These processes happen unconsciously and in real-time. (I am ignoring here phonological processing for ease of illustration.)

Acquisition proceeds in the following manner: Learners process and parse input they hear or read, and the processed data are used by Universal Grammar to determine appropriate values (parameters) of the language and to ensure that the language obeys the properties of all human languages. Again, this is deceptively simple. A number of questions arise.

- How do learners parse and process incoming data if they have no grammar of the language being learned? The basic question here is what the starting point for processing input in the L2 context is. Learners can rely on universal aspects of processing and parsing or they may rely on an L1 parser and set of processors. There might even be some combination of universal and L1-based processing involved (see, for example, Carroll, 2003, as well as VanPatten, 2007).

- What is the role of the L1 in the interaction of input, processing/parsing, and UG? Some scholars believe that learners begin acquisition by transferring all the properties of the L1 (i.e., all of its parametric values), and that the job of acquisition is to write over these values (i.e., reset parameters). Others believe the L1 operates at the level of processing as per the first question in this list. It could be that the L1 operates at all levels-in processing and in initial parametric values (see White, 2003).

- What elements trigger what within the context of UG? For example, does morphological development trigger syntactic development or is it the other way around? In the context of languages with rich verbal inflection (e.g., Spanish, Italian, Russian) some scholars claim that the acquisition of verbal inflections precedes and thus drives related syntactic operations (e.g., verb movement, null subject parameter). Others believe the opposite, although evidence is beginning to accumulate that abstract properties of syntax and their operations are in place before acquisition of morphological inflections is complete (VanPatten, Keating, \& Leeser, forthcoming).

- What about elements of language that are not governed by UG or are not necessarily part of a parametric variation? These may well be acquired in the same way as any other part of language. For example, research on lexical acquisition 
suggests that vocabulary is acquired incidentally through reading and interaction (i.e., as a byproduct of comprehension—see Coady \& Huckin, 1997).

- What role, if any, does speaking play in this scenario? The question here refers to Swain's well known Output Hypothesis as well as the research on interaction (Swain, 1985; Gass, 2003). Simply put, does speaking somehow trigger the development of grammar? The jury is out on this debate.

- Why does adult SLA look different from child L1A in terms of ultimate attainment and, in some cases, developmental paths? This particular question has invited a plethora of responses that cannot be summarized here. One major aspect of divergence between L1A and adult SLA seems to be the presence of an L1 in the adult SLA context, something that either affects the processing of input data or the actual hypotheses that learners make about language (see, for example, Herschensohn, 2009 for an excellent overview).

The above list is partial -and we are of course ignoring for illustrative purposes issues surrounding the social context of language learning and use. Nonetheless, while three ingredients are required for acquisition (input, parsers/processors, UG), what remains to be worked out are the details of how these work together (e.g., Carroll, 2001; Truscott \& Sharwood Smith, 2004), as well as how other factors work (or do not work) with them (e.g., Gass, 2003). In addition, while the three ingredients may be present, complete acquisition is not guaranteed. Non-native-likeness seems to be the norm among L2 speakers/learners (e.g., Herschensohn, 2008; Sorace, 2003; White, 2003). Just because a piece of data appears in the input does not mean it gets processed or gets processed correctly (e.g., VanPatten, 2004b, 2007). What is more, that a piece of data is processed does not mean that UG makes use of it immediately (e.g., Hawkins, 2001). The reasons for these situations are not clear, although evidence is converging on the role of the L1 in complicating SLA, in both processing and in how UG works (e.g., Herschensohn, 2008; Sorace, 2003; White, 2003), as well as other factors (VanPatten, forthcoming).

\section{I.3 Is the Development of Mental Representation Amenable to Instruction?}

As defined here, mental representation is not amenable to manipulation from the outside; however this does not mean that instruction cannot make a difference in some way (probably indirectly). To clarify, UG — as part of the language faculty - operates only on processed data from the input; it cannot operate on information about the language (Schwartz, 1993; White, 1989, 2007). Thus, UG-related aspects of acquisition are not susceptible to external 
influences such as explicit information, drilling, correction, and other means by which many instructional formats attempt to induce learning. Parsers and processors, too, operate only on input data. They are designed to tag language, and like UG they do not operate on information about the language, nor do they operate on explicit error correction or output. This scenario is akin to the systems that read bar codes in a grocery store. The scanner reads the striped bar codes -ignoring surrounding print, pictures, labels, and other visual information the scanner is not designed to read. This is what parsers and processors do with input; they read only what they are designed to read and ignore everything else. The bar code scanner then sends the data to a computation device that converts it into information that can be used by the register. This is what UG does with processed input data. The important point here is that the scanning system is designed for one and one purpose only, and each of its components responds to only certain kinds of data. The language faculty of the human mind is also designed for one purpose only and it responds to only certain kinds of data (see Schwartz 1993 and also the discussion in VanPatten, 2010). In the case of do-support in English, teachers can and do teach $d o$, and learners can and do take tests on what they learn. What we are saying is that although you can teach do, what you can't teach are the abstract underlying features such as +/-STRONG in CP, Tense, or any other syntactic phrase, as well as why English questions behave the way they do. This knowledge is derived implicitly from interaction with the language.

This scenario leaves us with the question of input. If the language processors can only operate on input data, and if UG only operates on the data delivered to it by the processors, can we manipulate the input in some way in order to push acquisition along? Theoretically this is possible, and some promising avenues have been explored, such as processing instruction (Benati \& Lee, 2008; VanPatten \& Cadierno, 1993; VanPatten, 2004a, 2009; among many others). Processing instruction provides manipulated input (called structured input) such that the processors are forced to process data in ways they might not under naturalistic conditions. The result of processing instruction is richer "intake"; that is, data useable by UG. Although processing instruction often provides explicit information as part of the treatment, research on processing instruction has repeatedly shown that this information is not needed. Structured input alone is sufficient to cause changes in learner knowledgewhich is predicted by the very nature of acquisition (i.e., input + processors + UG) (see, for example, Fernández, 2008; Henry, Culman \& VanPatten, 2009; VanPatten \& Oikennon, 1996, and various papers in VanPatten, 2004a).

To be sure, the point of any input manipulation - be it processing instruction or any other kind - is not to promote the development of communicative ability. The point of manipulating input is to alter the data used by the processors and by UG in the development 
of a mental representation. The development of communicative ability falls outside of the realm of mental representation, although presumably language use requires some kind of underlying mental representation. We turn our attention to language as skill.

\section{LANGUAGE AS SKILL}

\section{II.1 What is Skill?}

I use skill as it is normally used in the literature on cognitive psychology; that is, the speed and accuracy with which people can perform certain actions or behaviors (Anderson, 2000; Schmidt, 1992; Segalowitz, 2003). Skills can be general (e.g., problem solving, learning) or they can be domain- or context-specific (e.g., cooking omelets at a restaurant, mixing margaritas in a bar, delivering a speech). Regardless of generality or specificity of domain, that skill involves both speed and accuracy is important -and how skill is measured considers both how quickly someone can do something and how well (the "how well" being contextually defined). A person very skilled in making omelets is not only accurate but generally speedy (i.e., the omelet comes out just right and the person doesn't take long to produce it). A person not skilled in making omelets may be accurate but exceedingly slow, or may be quick but inaccurate, or may be both slow and inaccurate, and these variations may be classified as "more or less skilled" depending on the needs of the person making the classification. (e.g., someone who is slow but makes a good omelet may be classified as "more skilled" than someone who is fast but makes a lousy omelet).

In the case of language, skill refers to communication in all of its manifestations: interpretation (reading, listening), expression (writing, speaking), and negotiation (conversational interaction, turn taking). Note that some of these can be context specific. For example, writing in a chat room is not the same thing as writing this essay. Reading clues for a cross-word puzzle is not the same thing as reading Plato's Phaedo for an oral report in a classics course. Speaking while ordering a meal is not the same thing as speaking during an interview with a commentator of a national news broadcast. Thus, when we speak of language skills we must ask ourselves, “Language as skill for what purpose and in what context?” And just like cooking omelets, language as skill involves both speed and accuracy. A skilled reader of Plato reads quicker than an unskilled reader and makes few(er) mistakes in interpreting the text. A skilled essay writer produces text faster than the unskilled writer and makes few(er) mistakes (in style, punctuation, word choice, collocation, ambiguity, and so on). 
What is interesting about language skill with native speakers and also makes it different from, say, beginning learners of an L2 is that the native speaker has a relatively mature mental representation of language in place prior to skill onset (with the exception of basic conversational skills). Whether a native speaker is skilled at reading cross-word clues or at reading Phaedo, the mental representation for language (e.g., syntax, morphology, phonology) was in place before the skill was developed. As established in first language research, most of the mental representation for the formal properties of language exists by the time a child begins school. This is not the case for the beginning L2 learner, especially the classroom learner. Long before a mental representation is in place, learners are asked to read, write, listen, and speak using language that is far beyond their underlying representation.

\section{II.2 How does Skill Develop?}

Assuming skill refers to an intersection of speed and accuracy, how skill develops in any domain depends on tasks in which people are engaged. What is understood from the literature is that skill develops with task- and context-appropriate behavior. A person learns to make omelets by making omelets. A person learns to write essays by writing essays (although it also seems that there is relationship between writing and reading; reading lots of essays may instill in the mind/brain of the writer an implicit template for essay writing). In short, people become skilled at doing something not by mechanistic activity, but by engaging in the very activity they would like to become skilled in —or at least engaging in behaviors that have some kind of "transfer appropriateness" (Segalowitz, 2003).

To be sure, one hears of "drilling”, which is a kind of mechanistic activity in which a piece of the skill is isolated and practiced apart from the context in which it is used. In tennis, for example, a player in training might hit repeated backhands against a ball machine in order to work on the backhand technique. What makes this different from drills that occur in classrooms is that the tennis player in training already has backhand knowledge; that player is perfecting something. No tennis player in training at the beginning spends the first day drilling a backhand. Tennis players begin training by playing tennis. The perfection of technique comes later. This is different from what often happens in classrooms, in which learners engage in low-level mechanistic activities devoid of communicative purpose or goal from the get go, where accuracy supposedly precedes communication, a questionable practice (e.g., DeKeyser, 1998). 


\section{II.3 Is Skill Development Amenable to Instruction?}

It is difficult to determine to what extent instruction has an effect on skill development (again, in all of its manifestations - expression, interpretation, negotiation). If skills develop because of engagement with the very behaviors that people would like to develop, then skills cannot be taught per se; teachers and materials can only provide opportunities for their development. If one defines instruction very loosely as "providing opportunities” then, yes, instruction can facilitate skill development. However, if one defines instruction in more traditional terms (e.g., as explicit intervention), then instruction probably can't impact skill development. For example, how does one explicitly "teach" comprehension to language students? What normally occurs is that comprehension simply happens to learners as they try to ascertain what someone else is saying. It is true that teachers can teach strategies for comprehension (e.g., gisting, going for key words, repeated listening/reading), but teaching strategies for coping with language that is above one's level is not the same thing as teaching comprehension itself. What is more, there is no definitive research that the teaching of isolated strategies actually leads to comprehension overall (pace Vandergrift \& Tafaghodtari, 2010, who argue for the effect of metacognitive process teaching on listening comprehension abilities, not particular skills within listening). The same can be said for speaking and writing.

In a native language, skill development happens not because of explicit teaching and intervention, but by providing appropriate opportunities. When children begin school, they learn to read by being given opportunities to read. To be sure, they may start with Dick and Jane in the earliest grades, making their way to Melville by secondary school (with a Harry Potter or Twilight romp in-between), but the point is they learn to read by reading. By reading I don't mean learning to make word-grapheme correspondences; by reading I mean weaving words into idea units and then weaving these smaller idea units into larger idea units to construct a meaning that is intended in the passage. This process is something much bigger than knowing that cat stands for $/ \mathrm{kæt} /$. Likewise, learning to write essays happens not because one is taught how to write essays but because one engages in writing essays. Again, to be sure, people might receive explicit feedback ("this was good”, “this point isn't clear”, "you don’t have a main sentence idea in this paragraph") which one can construe as some type of explicit intervention. What is not clear from the research, however, is to what extent this feedback actually impacts development (Williams, 2005). As alluded to earlier, there is a relationship between reading and writing in the L1 and it is not clear to what extent skilled adult writers are skilled writers because they received feedback on their writing or because they've read so much along the way. (It's worth pointing out that even skilled writers get their work copyedited.) 
In addition, with or without instruction, research is fairly clear that L2 learners never develop skill that is quite native-like. If we take reading, for example, as one type of skill, do L2 learners ever read like native speakers? The answer is "not really.” Although on some tests of comprehension, the performance of non-native readers is not significantly different from that of native readers, other research suggests something different. Sentence level interpretation research suggests that very advanced (i.e., long-time speakers/learners of a second language) may not process anaphoric reference the same way natives do. In Spanish and Italian, for example, there are null and overt subject pronouns. When these have multiple antecedents, Spanish speakers seem to demonstrate a preference: null subjects tend to be interpreted as co-referential with a previous subject (no topic shift) while overt subject pronouns tend to be interpreted as co-referential with non-subjects (topic shift). Thus, in Juan vio a Roberto después que (él) regresó de Francia ('John saw Robert after [he] returned from France'), the tendency of native readers is to have the null subject refer to Juan and the overt pronoun (él) refer to Roberto (e.g., Alonso-Ovalle et al., 2002; Carminati, 2002). Very advanced learners of Spanish and Italian tend not to make this distinction when reading or listening; both null and overt subject pronouns tend to be linked to the subject of the previous clause or sentence (e.g., Sorace \& Filiaci, 2006; Jegerski, VanPatten, \& Keating, forthcoming). Thus, a very subtle aspect of comprehension is missed.

And -just to be sure it is mentioned here- research using on-line measures such as eyetracking and self-paced reading has repeatedly demonstrated that even though native speakers and non-native speakers might arrive at the same comprehension of sentences, non-native readers are consistently slower than natives in reading sentences no matter how advanced the former are (e.g., Frenck-Mestre, 2005).

Finally, as stated earlier, L1 learners arrive at formal schooling with a mental representation for the formal aspects of language pretty much in place. A few peripheral features of language may be missing (e.g., passive structures in English, certain morphological inflections in Russian) but the underlying representation that allows for these things to be incorporated into language are already there. What happens to L1 speakers after the onset of formal education is not so much the development of the formal properties of language, but the continued development of skills that involve discourse, vocabulary, pragmatics, interaction, reading, writing, and other things. These things assume an underlying formal system. In the L2 context, this scenario is not the same. Whereas the sequence in L1 is generally mental representation precedes skill (e.g., reading, writing), in L2 circles there is no sequence; mental representation and skills are pushed at the same time (at least for literate learners). 
So far, we have been talking about skill in its broadest sense. In the next section, I touch upon an aspect of language instruction that I think represents a confusion or conflation of concepts. That confusion involves applying the concept of skill to formal properties of language.

\section{A CONFUSION IN THE PROFESSION}

As defined earlier, the formal properties of language are not skill; they exist as mental representation. However, it is not clear to me that teachers, textbooks, and many researchers in instructed SLA see the formal properties of language in this manner. I begin with a discussion of teaching.

\section{III.1 Grammar as Skill in Teaching}

For most (if not all) language teaching professionals, there is the belief that textbook rules are somehow representative of what winds up in learners' minds/brains. This idea dates back to the concepts of "skill-getting", as espoused by teaching methodologists in the 1970s and 1980s (e.g., Omaggio, 1986; Rivers, 1981). The concept still permeates most of language instruction practices today when one examines typical foreign language textbooks for adults. Let's return to our earlier example from English. When teachers teach something like dosupport in English, many believe that the rules they provide are the rules that underlie both representation and production. Thus, by teaching and practicing the rule, learners acquire the rule. The idea here is that the grammar is the skill to be acquired. But is it the case that the pedagogical rules for do-support are what exists in the mental representation for language? The answer is "they cannot." Do-support is a syntactic reflex of several aspects of abstract syntax: that English has strong Tense features (that is, tense must always be represented somehow in a finite clause), but also has weak Agreement features (that is, there is no clear mapping of person-number features in English onto verbs except for the irregular verb be in the present tense). These two underlying features of English force do insertion in emphatic statements as well as yes-no questions. The reason for this is that some kind of finite verb must carry tense features (the strong Tense issue) and lexical verbs (as opposed to auxiliaries and modals) in English cannot move to create subject-verb inversion in questions as is the case with languages like Spanish (the weak Agreement issue). In short, learners must create (and do create) abstract underlying syntactic representations that have little to do with textbook rules (e.g., Herschensohn, 2000; Rothman, Judy, Guijarro-Fuentes, \& Pires, 2010). 
This simplified description of do-support is one example that begs the question: then what "skill" is it that learners are getting when they are practicing pedagogical grammar rules? If pedagogical rules don't exist in the head, then what are learners learning to do as part of their skill? My point here is that by moving grammar into the realm of skill acquisition (as opposed to real skill acquisition-production skills and comprehension skills as part of communication), teachers and theorists conflate two constructs that really aren't supposed to be conflated. In short, grammar as the formal properties of language is not a "skill” to be acquired; it is knowledge (as abstract and implicit mental representation) that is tapped during linguistic performance (see the discussion above in II.3).

This leads me to a discussion about speaking as skill. The usual conceptualization of speaking as skill conflates grammar acquisition with skill development (e.g., DeKeyser, 1997; Rivers, 1990). That is, the classic paradigm for the ability to speak involves grammar as declarative knowledge, that then gets proceduralized, that then gets automated. It is in the proceduralization to automatization stage that we see the beginning of skill development with grammar, with automatization suggesting some kind of fluency DeKeyser, 1997). There are two observations I would like to make here. The first is that it is not clear to me that this particular scenario is the correct one for how grammatical "stuff" gets used in real time. As mentioned above, the mental representation that people carry around in their heads for language does not look like any rules at all, so rules per se aren't even internalized under current thinking about both language and language acquisition. Yet, most skill theory research uses rules that are a-theoretical in content; sometimes these are pedagogically-oriented rules, sometimes rules from a structural description, but they are never derived from linguistic theory. For example, in DeKeyser (1997), participants explicitly learned and then practiced four isolated grammar rules for an artificial miniature language. Training and practice lasted for 22 sessions of one hour or less (over 11 weeks). His results clearly showed the typical learning curves observed in skill research and his conclusion was that "the learning of second language grammar rules can proceed very much in the same way that learning in other cognitive domains, from geometry to computer programming, has been shown to take place" (p. 214). Although this conclusion is indisputable for his particular study, there is a larger problem here when interpreting this kind of research in the real world of language acquisition. The first is that, again, learners don't have rules in their heads like textbook rules and the rules that were used in DeKeyser's study. These rules are artificial, mere shorthand ways for us to talk about language that is too complex to talk about to students. The second problem is that language acquisition does not proceed by learning isolated rules. At any given time, learners are working on a variety of things in language, from phonology (including prosody), to morphology, to underlying syntax, and so on. The learner's mind/brain does not stop and 
say "Let's just work on this one thing until we get it right." So, while the results of skill research are suggestive about what happens in laboratory settings, it's not clear that they speak to issues related to both what language is and how such a complex thing is acquired outside the laboratory.

The perspective taken in skill theory in which isolated bits of language are learned and practiced stands in stark contrast to research from a generative perspective, for example, in which the relationship between surface features of language (e.g., tense markers on verbs, person-number markers on verbs, pronoun case) is linked to underlying functional features (e.g., finiteness, strong versus weak tense, strong versus weak agreement). For example, Lardiere (2007) argues that her subject -who appears to be a fossilized speaker of English L2 with Chinese L1- shows clear underlying mental representation for the functional features, but that the interface between the mental representation and spell out (e.g., the phonetic and acoustic realization of underlying phonological representations) is compromised in some way. In our recent research (VanPatten, Keating, \& Leeser, forthcoming), we use on-line processing as a measure of grammatical sensitivity, comparing native and mid-level nonnative speakers of Spanish on syntactic and morphological features related to strong agreement. Our results were very clear: native speakers showed sensitivity to violations in all domains (three features of syntax plus subject-verb agreement); the non-natives showed the same sensitivities to syntactic violations but not to the subject-agreement violations. What makes the results of this experiment interesting is this: the learners never practice or explicitly learned the syntactic aspects we tested yet they had explicitly learned and had practiced (including feedback) on subject-verb agreement since the beginning of their language studies. In short, they acquired that which they weren't taught and yet were unable to show sensitivity to the things they had been taught and they had practiced. A skill theory approach to the acquisition of grammar has difficulty accounting for something like Lardiere's research as well that of VanPatten, Keating, and Leeser, unless of course, one sweeps linguistic theory under the rug.

At the same time, a skill theory perspective ignores some important research that has emerged on speech (output) processing in SLA, namely Processability Theory (e.g., Pienemann, 1998, 2005). Within Processability Theory, the emergence of grammatical operations in learner output (e.g., agreement of an adjective with a noun, agreement of a verb with its subject) is constrained by a universal implicational hierarchy. The complex interaction of this hierarchy with a learner's mental representation yields staged development, and staged development is not predicted by skill theory as applied to grammatical features of language. To be sure, Processability Theory is concerned with the emergence of grammatical operations in learner output and not with the development of skill per se, but it seems that 
some kind of reconciliation of the two perspectives on how learners learn to speak is in order. Currently, I don't see such a reconciliation happening in the near future.

The second observation I would like to make about the application of skill theory to grammar acquisition and use is perhaps more important than the previous observation: Is the correct use of surface features of language in real-time speaking a simple matter of automatization of grammatical operations? Schmidt (1992) suggested that fluency may indeed involve such automatization, but speaking (output) in general — especially by native speakers, and one would presume this would apply to non-native speakers as well- can't be a simple application of grammatical rules in real time. That is, a good deal of fluency must involve the use of chunks and phrases of language that are stored as such; not all language production must or can involve word by word sentence formulation. What is more, Schmidt cautioned the field against the importation of constructs from psychology that may not have relevance to language and language teaching:

...it is unsettling to realize that the mechanisms made available by psychological theorizing for understanding L2 fluency derive primarily from the study of skill in such tasks as typing, the detection of target letters in fields of distractors, judgments about digital logic gates, alphabet arithmetic, and computer simulations of the same tasks, tasks that cannot be assumed to rely necessarily on the same learning mechanisms as speaking a second language (p. 378-379)

Eighteen years later, Schmidt's concern is still valid. There are but a handful of studies that actually address skill development from a second language perspective, and-as noted above- their focus on discrete points of language gives pause in terms of their applicability to actual skill development as described at the outset of this section. We are still importing ideas and paradigms from psychology that may not be valid for the complexity (and subtlety) that is language acquisition.

\section{CONCLUSION}

In this article I have argued that there are two distinct aspects of acquisition. One involves the acquisition of an abstract and implicit mental representation —what linguists traditionally call competence. The other is skill — the ability to use language fluently (measured by speed and accuracy) in both production and comprehension. I have also argued that mental representation evolves one way (input + processors + UG) while skill evolves in another (use of language in particular contexts). I have also argued that mental representation is not amendable to instruction as normally conceived. I have also argued that skill itself is not teachable in a direct sense, although classroom activities can be provided that facilitate its 
development. Finally, I have argued that many teachers and some scholars mistakenly (in my view) attempt to apply skill theory to the acquisition of grammar, when grammar is not a skill but a mental representation.

For those who are looking for implications for language instruction or curriculum development, I am hesitant to make any based on this one essay, preferring to let methodologists draw their own conclusions. That is, I am not making any arguments for particular curricula, approaches, or methods. I have, however, argued that neither language as mental representation nor language as skill can be directly taught. Teachers and materials cannot directly intervene in the development of either. Instead, both mental representation and skill evolve in learners based on the experiences the latter receive in and out of classrooms. My argument, then, is that the research allows teachers to explore and test for themselves the various options available in the literature on instruction. Understanding how acquisition works allows teachers and curriculum developers to be better informed consumers of the latest trends in language teaching.

One thing that should be clear, I hope, is that language is not a simple monolithic entity and that different parts of it -in this case mental representation and general skill, with each of these having their own subcomponents- most likely respond to different treatments; and in some cases, they may be immune to particular direct and explicit attempts at their induction. It is up to continued research to determine whether particular sub-components of either representation or skill can be affected by instructional intervention.

\section{REFERENCES}

Alonso-Ovalle, L., Fernández-Solera, S., Frazier, L., \& Clifton Jr., C. (2002). Null vs. overt pronouns and the topic-focus articulation in Spanish. Rivista di Linguistica, 14(2), 151-169.

Anderson, J. (2000). Learning and memory. (2nd ed.). New York: John Wiley \& Sons.

Benati, A. \& Lee, J. F. (2008). Grammar acquisition and processing instruction: secondary and cumulative effects. Bristol: Multilingual Matters.

Carminati, M. N. (2002). The processing of Italian subject pronouns. Unpublished doctoral dissertation. University of Massachusetts at Amherst.

Carroll, S. (2001). Input and evidence: The raw material of second language acquisition. Amsterdam: John Benjamins.

Chomsky, N. (1995). The minimalist program. Cambridge, MA: MIT Press.

Coady, J. \& Huckin, T. (Eds.). (1997). Second language vocabulary acquisition. Cambridge: Cambridge University Press.

DeKeyser, R.M. (1997). Beyond explicit rule learning: automatizing second language morphosyntax. Studies in Second Language Acquisition, 19(2), 195-222.

DeKeyser, R.M. (1998). Beyond focus on form: Cognitive perspectives on learning and practicing second language grammar. In C. Doughty \& J. Williams (Eds.), Focus on form in classroom second language acquisition (pp. 42-63). Cambridge: Cambridge University Press.

Fernández, C. (2008). Re-examining the role of explicit information in processing instruction. Studies in Second Language Acquisition, 30(3), 277-305. 
Frenck-Mestre, C. (2005). Eye-movement recording as a tool for studying syntactic processing in a second language: a review of methodologies and experimental findings. Second Language Research, 21(2), 175-198.

Gass, S. M. (2003). Input and interaction. In C. Doughty \& M. H. Long (Eds.), The handbook of second language acquisition (pp. 224-255). Oxford: Blackwell.

Harley, H. \& Noyer, R. (1999). Distributed Morphology. Glot International, 4(4), 3-9.

Hawkins, R. (2001). Second language syntax: A generative introduction. Oxford: Blackwell.

Henry, N., Culman, H. \& VanPatten, B. (2009). More on the effects of explicit information in instructed SLA: A partial replication and response to Fernández (2008). Studies in Second Language Acquisition, 31(4), 559-576.

Herschensohn, J. (2000). The second time around: minimalism and L2 acuqisition. Amsterdam: John Benjamins.

Herschensohn, J. (2008). Language development and age. Cambridge: Cambridge University Press.

Herschensohn, J. (2009). Fundamental and gradient differences in language development. Studies in Second Language Acquisition, 31(2), 259-289.

Jackendoff, R. (2002). Foundations of language. Oxford: Oxford University Press.

Jegerski, J. , VanPatten, B. \& Keating, G.D. (forthcoming). L2 processing of anaphoric pronouns: L1 transfer at the syntax-discourse interface. Submitted to Second Language Research.

Lardiere, D. (2007). Ultimate attainment in second language acquisition. Mahwah, NJ: Lawrence Erlbaum Associates.

Omaggio, A. M. (1986). Teaching language in context. Boston: Heinle \& Heinle.

Pienemann, M. (1998). Language processing and second language development: Processability Theory. Amsterdam: John Benjamins.

Pienemann, M. (Ed.). (2005). Cross-linguistic aspects of Processability Theory. Amsterdam: John Benjamins.

Radford, A. (1997). Syntactic theory and the structure of English. Cambridge: Cambridge University Press.

Radford, A. (2001). Syntax: A minimalist introduction. Cambridge: Cambridge University Press.

Rivers. W. (1981). Teaching foreign language skills. Chicago: University of Chicago Press.

Rivers. W. (1990). Psychological validation of methodological approaches and foreign language classroom practices. In B. Freed (Ed.), Foreign language acquisition research and the classroom (pp. 283-294). Lexington, MA: D.C. Heath.

Rothman, J. (2010). Theoretical linguistics meets pedagogical practice: Pronominal subject use in Spanish as a second language. Hispania, 93(1), 52-65.

Rothman, J., Judy, T., Guijarro-Fuentes, P. \& Pires, A. (2010). On the (un)ambiguity of adjectival modifications in Spanish determiner phrases: Informing debates on the mental representation of syntax. Studies in Second Language Acquisition, 32(1), 47-77.

Schwartz, B. (1993). On explicit and negative evidence effecting and affecting competence and linguistic behavior. Studies in Second Language Acquisition, 15(2), 147-164.

Schmidt, R. W. (1992). Psychological mechanisms underlying second language fluency. Studies in Second Language Acquisition, 14(4), 357-385.

Segalowitz, N. (2003). Automaticity and second languages. In C. Doughty \& M. H. Long (Eds.), The handbook of second language acquisition (pp. 382-408). Oxford: Blackwell.

Sorace, A. (2003). Near-nativeness. In C. Doughty \& M. H. Long (Eds.), The handbook of second language acquisition (pp. 130-151). Oxford: Blackwell.

Sorace, A., \& Filiaci, F. (2006). Anaphora resolution in near-native speakers of Italian. Second Language Research, 22(3), 339-368.

Swain, M. (1985). Communicative competence: Some roles of comprehensible input and comprehensible output in its development. In S. M. Gass \& C. G. Madden (Eds.), Input in second language acquisition (pp. 235-253). Rowley, MA: Newbury House.

Truscott, J. \& Sharwood Smith, M. (2004). Acquisition by processing: A modular perspective on language development. Bilingualism: Language and Cognition, 7(1), 1-20.

Vandergrift, L. \& Tafaghodtari, M. H. (2010). Teaching L2 learners how to listen does make a difference: An empirical Study. Language Learning, 60(2): 470-497. 
VanPatten, B. (Ed.). (2004a). Processing instruction: Theory, research, and commentary. Mahwah, NJ: Lawrence Erlbaum Associates.

VanPatten, B. (2004b). Input processing in SLA. In B. VanPatten (Ed.), Processing instruction: Theory, research, and commentary (pp. 5-31). Mahwah, NJ: Lawrence Erlbaum Associates.

VanPatten, B. (2007). Input processing in adult second language acquisition. In B. VanPatten \& J. Williams (Eds.), Theories in second language acquisition (pp. 115-135). Mahwah, NJ: Lawrence Erlbaum Associates.

VanPatten, B. (2009). Processing matters in input enhancement. In T. Piske \& M. Young-Scholten (Eds.), Input matters in SLA (pp. 47-61). Bristol: Multilingual Matters.

VanPatten, B. (2010). Stubborn syntax. In C. Sanz \& R. Leow (Eds.), Proceedings of the GURT 2009. Washington, D.C.: Georgetown University Press.

VanPatten, B. (forthcoming). Adult second language acquisition. Linguistic Approaches to Bilingualism.

VanPatten, B. \& Benati, A. (2010). Key terms in second language acquisition. London: Continuum.

VanPatten, B. \& Cadierno, T. (1993). Explicit instruction and input processing. Studies in Second Language Acquisition, 15(2), 225-244.

VanPatten, B., Keating, G. D., \& Leeser, M. J. (forthcoming). The use of on-line measures of grammatical sensitivity to test the morphology-syntax interface. Submitted to Linguistic Approaches to Bilingualism.

VanPatten, B. \& Oikkenon, S. (1996). Explanation versus structured input in processing instruction. Studies in Second Language Acquisition, 18(4), 495-510.

White, L. (1989). Universal grammar and L2 acquisition. Amsterdam: John Benjamins.

White, L. (2003). Second language acquisition and universal grammar. Cambridge: Cambridge University Press.

White, L. (2007). Linguistic theory, universal grammar, and second language acquisition. In B. VanPatten \& J. Williams (Eds.), Theories in second language acquisition (pp. 37-55). Mahwah, NJ: Lawrence Erlbaum Associates.

Williams, J. (2005). Teaching writing in second and foreign language classrooms. New York: McGraw-Hill. 